\title{
REORGANIZAÇÃO ESPACIAL DA OFERTA ESCOLAR: O FECHAMENTO DE ESCOLAS RURAIS NO ESTADO DO RIO DE JANEIRO
}

\section{Reorganización espacial de la oferta escolar: la clausura de las escuelas rurales en el estado de Rio de Janeiro.}

\author{
Tássia Gabriele Balbi de Figueiredo e Cordeiro - FFP/UERJ \\ Mestra em Educação pelo PPG-Edu da Faculdade de Formação de Professores da UERJ \\ tassia.cordeiro@gmail.com
}

Artigo recebido em 09/09/2013 e aceito para publicação em 20/12/2013

DOI: 10.12957/tamoios.2013.7383

RESUMO

Este artigo, desenvolvido a partir da pesquisa do mestrado acadêmico no Programa de PósGraduação em Educação da FFP/UERJ, teve por objetivo analisar o processo de fechamento de escolas rurais e nucleação escolar no estado do Rio de Janeiro, sendo um de seus efeitos a reorganização espacial da oferta escolar, de modo a restringi-la nos espaços rurais concentrando-a em espaços urbanos. Para tanto, realizou-se um levantamento de dados junto aos Indicadores Demográficos e Educacionais do MEC, no qual foi possível verificar a expansão do processo de fechamento de escolas rurais no estado analisado, no período entre 2007 e 2010. Por meio dos dados foram elaboradas tabelas, gráficos e mapas ilustrativos que demonstram a espacialidade da retração da oferta escolar rural em grande parte dos municípios do Rio de Janeiro conformando uma mudança na espacialidade da oferta escolar e provocando uma política de esvaziamento do campo, uma clara negação às resoluções vigentes acerca da nucleação escolar e ao direito à educação. As reflexões acerca dos resultados da pesquisa quantitativa e das análises desenvolvidas indicam a efetividade do processo de nucleação de escolas rurais, o que é um dos reflexos das tensões que envolvem Estado e movimentos sociais populares do campo e, consequentemente, embates entre educação rural e educação do campo. Palavras-Chave: Nucleação Escolar, Reorganização Espacial, Políticas Públicas, Educação do Campo.

RESUMEN Este artículo fue desarrollado a partir de la investigación de maestría realizada en el Programa de Posgrado en Educación de la FFP/UERJ. Tuvo como objetivo analizar el proceso de cierre de las escuelas rurales y la nucleación de escuelas en el estado de Rio de Janeiro, concluyendo que uno de sus efectos principales fue la reorganización espacial de la oferta escolar, con la intención de restringirla en los espacios rurales y concentrarla en espacios urbanos. Para si llegar a ese resultado, fue realizado un análisis de los datos de los Indicadores Demográficos y Educativos del MEC, y así fue posible comprobar la expansión del proceso de cierre de las escuelas rurales en el estado analizado, entre 2007 y 2010. De acuerdo con estos datos fueron elaborados tablas, gráficos y mapas ilustrativos que confirman la sustracción de la oferta escolar rural en gran parte de los municipios de Rio de Janeiro, donde la consolidación de ese cambio provoca una política de vaciamiento del campo, que se choca directamente con las resoluciones vigentes sobre la nucleación escolar y el derecho a la educación. Los razonamientos delante de los resultados de la investigación cuantitativa y de los análisis desarrollados indican la efectividad de los procesos de nucleación de las escuelas rurales, que es un reflejo de las tensiones que involucran Estado y movimientos sociales populares de campo y, consecuentemente, oposición entre la educación rural y la educación del campo.

Palabras claves: Nucleación de Escuelas, Reorganización Espacial, Políticas Públicas, Educación del Campo. 


\section{INTRODUÇÃO}

O campo brasileiro está em movimento. Movimento este que põe em xeque as atuais estruturas de poder ao questionar o que está posto, invertendo a lógica dominante ao mesmo tempo em que propõe outra lógica. Uma das pautas presentes nas lutas dos movimentos sociais do campo, que colocam em movimento o Brasil rural, é a educação, e não qualquer educação e sim uma educação do campo (CALDART, 2012).

A nucleação de escolas rurais é uma política educacional que consiste no fechamento de escolas no campo com a transferência dos alunos das escolas desativadas para escolas núcleo, muitas vezes localizadas em áreas urbanas. Esta política tem como justificativa a precariedade das escolas situadas no campo brasileiro, envolvendo, da mesma forma, aspectos financeiros e administrativos.

Este artigo apresenta os resultados de pesquisa concluída em mestrado acadêmico, realizada no Programa de Pós-Graduação em Educação da Faculdade de Formação de Professores da UERJ ${ }^{\mathrm{ii}}$ que dizem respeito ao processo de fechamento de escolas rurais no estado do Rio de Janeiro tendo por objetivo analisá-lo e discuti-lo, refletindo acerca de seus resultados, com vistas a contribuir para o debate em torno da questão.

Os dados apresentados dizem respeito ao levantamento dos Indicadores Demográficos e Educacionais (IDE) do Ministério da Educação (MEC), que disponibilizam os números de escolas rurais de educação infantil, ensino fundamental e médio e o total de escolas rurais, por estados e municípios, entre 2007 e 2010. Cabe ressaltar que existem limitações no levantamento e na disponibilização de dados que não permitem uma análise mais abrangente. No entanto, tendo por base os dados disponibilizados, foram elaboradas tabelas, gráficos e mapas ilustrativos que demonstram as mudanças ocorridas na oferta escolar no período analisado, subsidiando em parte a tese de que o estado encontra-se num processo de reorganização espacial de sua oferta escolar.

A luta por educação do campo encontra, deste modo, desafios práticos. Se por um lado aumenta o movimento de luta por escolas e educação do campo, por outro há a retração da oferta de escolas rurais, o que aponta uma dualidade da política educacional brasileira: projetos governamentais que defendem a construção de escolas no campo, como o Pronacampo ${ }^{\text {iii }}$, contrastam com a política educacional mais posta em prática no meio rural, o fechamento e nucleação de escolas. Neste contexto surgem as tensões, os conflitos e a disputa por escolas.

\section{ESCOLA RURAL: UM TERRITÓRIO EM DISPUTA}

$\mathrm{Na}$ análise dos dados quantitativos e do processo de fechamento de escolas rurais, os conceitos geográficos mostram-se ferramentas essenciais para a reflexão e compreensão do processo. A escola rural, um território jurídico-político do Estado não deixa de estar carregado de um potencial simbólico que pode ser apropriado pelas comunidades rurais e muitas vezes disputado pelos movimentos sociais. Mesmo sendo um território estatal pode, no jogo das contradições espaciais, conter territorialidades contra-hegemônicas.

Dada a importância da instituição escolar, espaço público importante em uma comunidade rural, delineia-se uma disputa por este território. Uma disputa por sua dimensão simbólica: de um lado o Estado, impregnado da política de educação rural pautada na precariedade e na fragilidade pedagógica, e de outro os movimentos sociais, principalmente o Movimento dos Trabalhadores Rurais Sem Terra (MST), na construção do projeto de educação do campo.

A escola rural encontra-se em meio a contradições. A concentração fundiária e a falta de perspectivas para os jovens do campo determinam em parte o êxodo rural. Consequentemente, o 
esvaziamento do campo esvazia também a escola rural, soma-se a este fato as questões financeiras e administrativas que envolvem o estabelecimento de escolas no campo e um dos resultados tem sido o fechamento, muitas vezes arbitrário, destas. Mas, a questão parece bem mais profunda, ou seja, o fechamento da escola rural, transformada em mais uma ruralidade de espaços vazios (WANDERLEY, 2001), aquece a engrenagem perversa que diminui e esvazia com mais intensidade as perspectivas de vida no campo. Por fim, este processo pode desestabilizar e esvaziar o próprio movimento de luta. Sem escola no campo não há disputa por seu projeto educacional, a escola da cidade cumpre o papel simbólico-cultural definido pelo Estado.

O fechamento de escolas rurais é, portanto, uma desterritorialização (HAESBAERT, 2011), que envolve uma reterritorialização (HAESBAERT, 2011) destas escolas em escolas núcleo, isto é, escolas que agregam os alunos das escolas nucleadas/fechadas, tanto em áreas rurais quanto urbanas. Este fato gera uma reorganização espacial, uma concentração de escolas em poucas áreas rurais que são os núcleos do processo e, principalmente, uma concentração em áreas urbanas, tanto em escolas núcleo quanto em escolas urbanas em geral. Dessa forma, enquanto a oferta de escolas rurais retrai, por outro lado, há uma expansão da oferta escolar urbana e das matrículas da população rural nestas escolas, por vezes viabilizada por meio do transporte escolar.

A disputa pelo território escolar no campo, por parte dos movimentos sociais, sofre um duro golpe. Com a desterritorialização das escolas rurais, como pontuado, há a configuração de ruralidades de espaços vazios, o que acarreta no desaparecimento do sentido social que constitui uma escola, sentido este disputado pelo projeto de educação do campo, que nesta disputa procura transformar territórios escolares em contraespaços (MOREIRA, 2011).

O contraespaço é o modo espacial por meio do qual excluídos e dominados põem em questão a ordem espacial instituída como forma de organização da sociedade, rejeitando ou copiando o modo de vida que ela impõe aos que vivem embaixo e dentro dela. Pode ser contraespaço um movimento de confronto, de resistência, de mimetismo ou de simples questionamento da ordem existente. (MOREIRA, 2011, p. 103).

Uma escola rural na qual o projeto de educação do campo consolida-se de forma orgânica constitui um questionamento não só da educação dominante, no caso a educação rural, como também questiona a ordem dominante como um todo. Os territórios ocupados pelos movimentos sociais populares do campo podem conformar-se, dependendo do grau de organicidade, em verdadeiros contraespaços, em espacialidad de resistencias (OSLENDER, 2002).

É fato, portanto, que a escola rural é um território em disputa. O Estado procura exercer e legitimar seu controle nesta disputa de duas diferentes vias: primeiro, ao permitir o fechamento destas escolas, acabando com a possibilidade de ocupação destas pela educação do campo, optando pela política de nucleação e transporte escolar, e segundo, ao assumir o projeto de educação do campo, abortando e tomando para si uma luta dos movimentos sociais, cooptando-a. Os movimentos sociais do campo na luta por uma educação do campo tentam ocupar este território estatal, ressignificando-o e transformando-o em contraespaço, e exigindo do Estado políticas públicas que garantam uma educação do e no campo de qualidade. Está posto, deste modo, o conflito.

\section{A REORGANIZAÇÃO ESPACIAL: APRESENTAÇÃO DOS DADOS FINAIS}

O levantamento e análise dos dados disponibilizados nos Indicadores Demográficos e Educacionais demonstram preliminarmente que o Estado parece estar ganhando esta disputa por meio 
da primeira via, ou seja, o fechamento de escolas rurais, apesar de oficialmente articular e promover de forma parcial políticas de educação do campo.

É inegável a expansão do processo de fechamento de escolas no Brasil rural em geral e no estado do Rio de Janeiro em particular. Os dados nos permitem aferir que este processo não se resume somente ao fechamento das escolas, mas em alguns casos ocorre também através da desativação de etapas de ensino. Neste contexto, é possível asseverar que está em curso um processo de fechamento e nucleação de escolas rurais, culminando na redução da oferta escolar e das matrículas no campo.

A etapa de educação infantil, devido sua importância para a formação e preparação para o ensino fundamental, vem se expandindo por conta do alargamento de sua demanda e de sua relevância para o desenvolvimento das crianças desta faixa etária. Muito embora tenha sido determinada sua obrigatoriedade para as crianças aos 4 anos de idade a partir de 2016, ao se analisar os dados acerca da oferta de educação infantil nos municípios do Rio de Janeiro (Gráfico 1), verifica-se que a maior parte destes (34\%) retraiu a oferta desta etapa entre 2007 e 2010, o que demonstra a gravidade do avanço deste processo, que acaba por impedir o direito à escolarização de parte da população rural.

Mesmo assim, uma parcela dos municípios expandiu a oferta (29\%), provavelmente devido às pressões sociais e educacionais que cada vez mais demandam por creches e pré-escolas, o que pesou na decisão de redução da obrigatoriedade da matrícula de 6 para 4 anos. Barbosa, Gehlen e Fernandes, ao refletirem sobre as demandas por educação infantil no campo consideraram que

No bojo dessas discussões também estão presentes as mudanças nas relações sociais e familiares, os questionamentos ao patriarcado, a crescente afirmação da mulher no trabalho e na vida social nas realidades rurais que contribuíram para colocar na agenda o direito das crianças pequenas à educação em espaços qualificados e coletivos (BARBOSA, GEHLEN, FERNANDES, 2012, p. 77).

Por fim, $26 \%$ dos municípios não alteraram a oferta de educação infantil no período e $11 \%$ não ofertaram esta etapa de ensino.

Gráfico 1

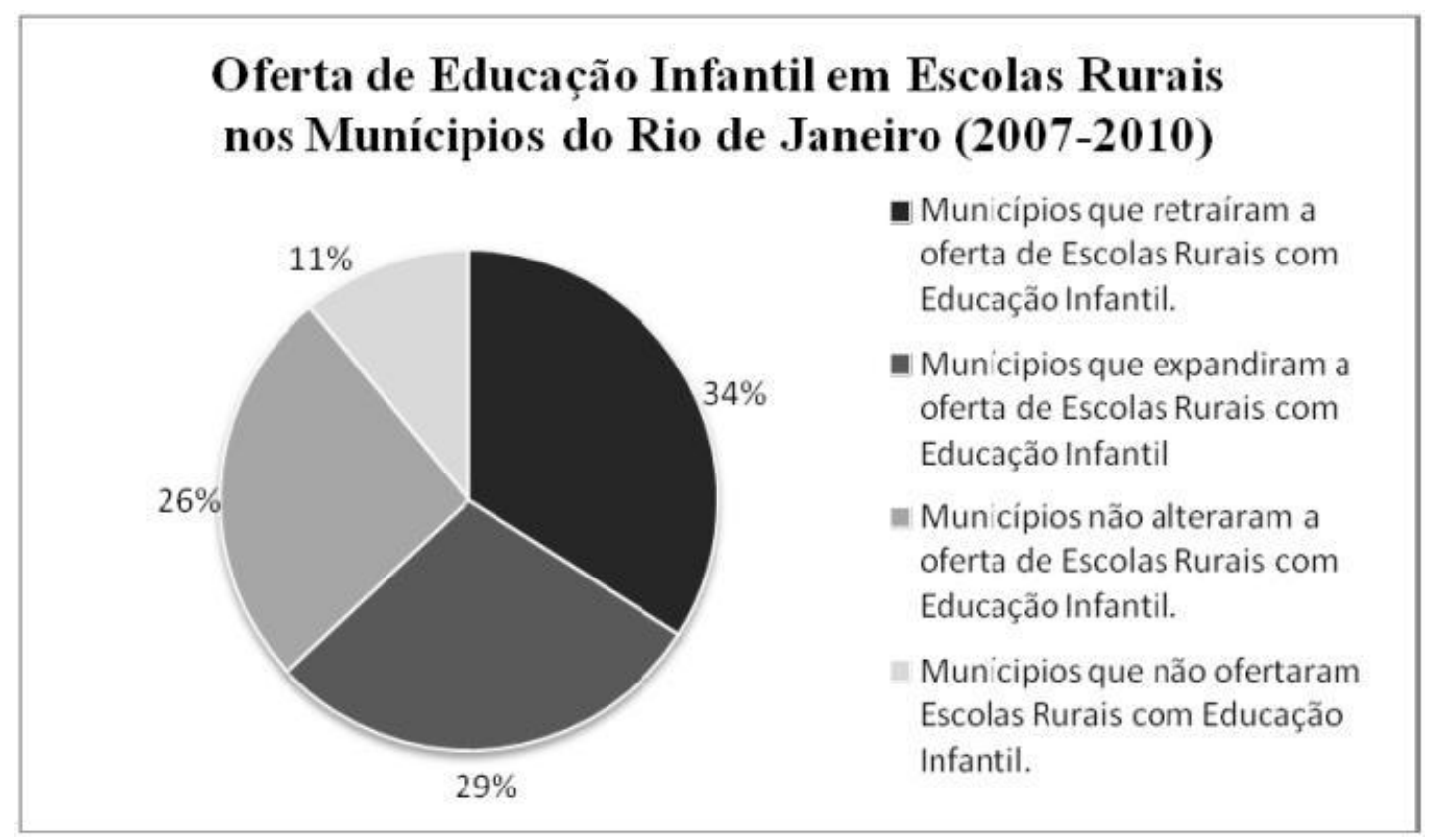

Fonte: Gráfico Organizado a partir de dados dos Indicadores Demográficos e Educacionais (MEC, 2011) 
No mapa 1 é possível visualizar espacialmente o processo, ao qual nos referimos anteriormente, sendo destaque a predominância do vermelho, representando os municípios que desativaram a etapa de educação infantil em suas escolas ou fecharam escolas que ofertavam esta etapa, e do amarelo escuro, representando os municípios que expandiram a oferta, ou seja, abriram escolas de educação infantil ou inseriram esta etapa em escolas que não a possuíam.

Por sua vez, a predominância do amarelo claro, indicativo da não alteração da oferta, juntamente com a do vermelho e a do amarelo escuro, indica que nesta etapa houve uma distribuição relativamente equilibrada entre estes três processos: retração, expansão e não alteração da oferta. Por fim, o mapa indica que uma minoria dos municípios não ofertou educação infantil em áreas rurais, sendo estes representados pela cor cinza.

Mapa 1

\section{Oferta de Educação Infantil em Escolas Rurais nos municípios do Rio de Janeiro (2007-2010).}

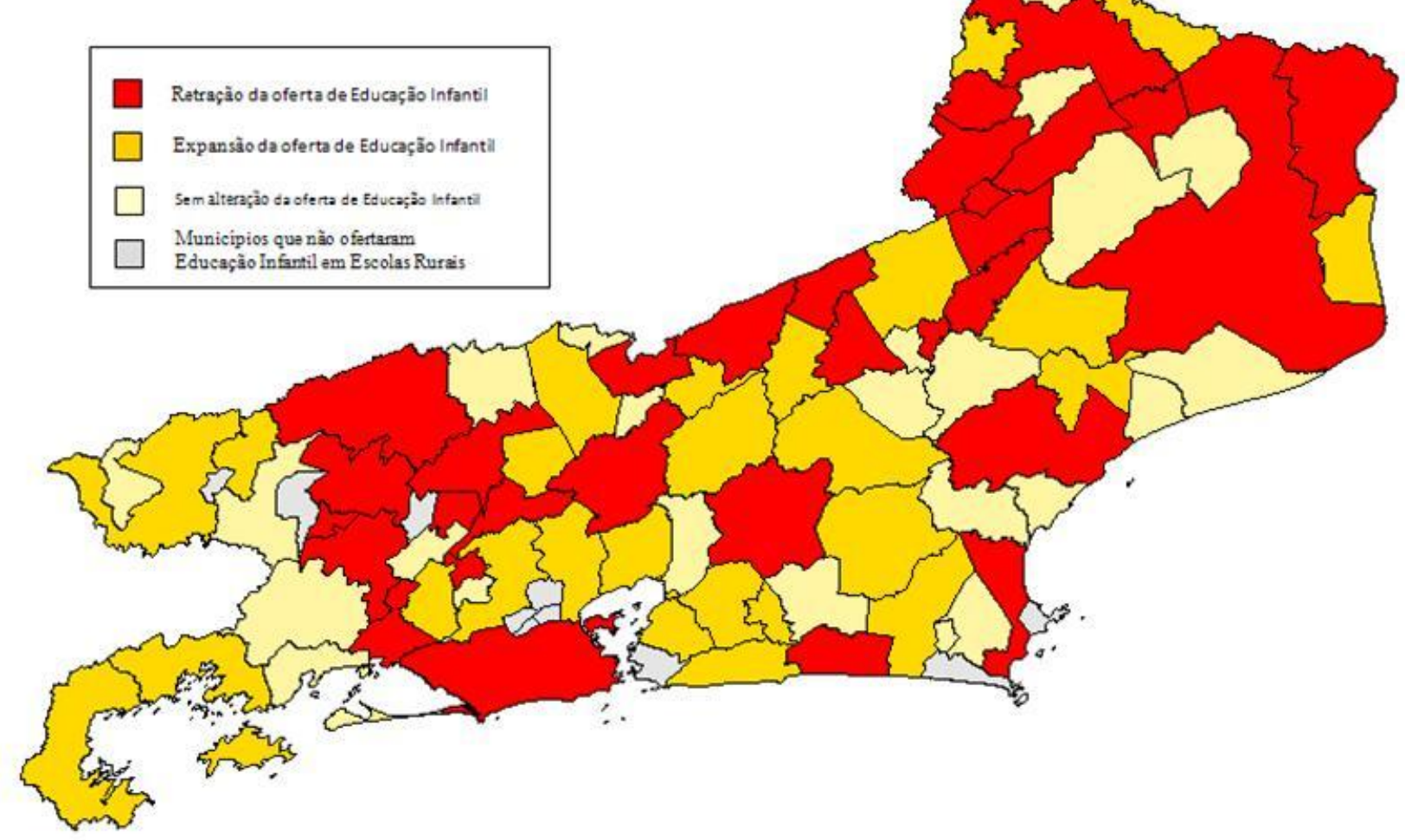

Fonte: Mapa elaborado a partir dos dados dos Indicadores Demográficos e Educacionais 2007-2010 (MEC, 2011).

Na tabela 1 é possível visualizar os municípios que lideraram a retração da oferta de educação infantil em escolas rurais, sendo Campos dos Goytacazes o líder do processo, pois diminuiu em oito o número de escolas rurais que ofertam esta etapa, seguido por São Francisco de Itabapoana, Macaé e Varre-Sai, e por fim, Sapucaia, Saquarema e Valença. 
Por meio da análise dos dados podemos considerar que a retração é menor na educação infantil, quando comparada com a retração das outras etapas, o que não faz o processo ser menos impactante. Sobretudo em se tratando de uma oferta que já é muito reduzida.

Tabela 1

Municípios do Rio de Janeiro que mais Desativaram a Etapa de Ensino de Educação Infantil (20072010)

\begin{tabular}{c|c|c}
\hline \hline Colocação & Municípios & $\begin{array}{c}\text { Número de Escolas e/ou Etapa de } \\
\text { Ensino (EI) Desativadas }\end{array}$ \\
\hline $1^{\circ}$ & Campos dos Goytacazes & 8 \\
\hline $2^{\circ}$ & São Francisco de Itabapoana & 6 \\
\hline $3^{\circ}$ & Macaé/Varre-Sai & 5 \\
\hline $4^{\circ}$ & Sapucaia/Saquarema/Valença & 6 \\
\hline \hline
\end{tabular}

Fonte: Tabela Organizada a partir de dados dos Indicadores Demográficos e Educacionais (MEC, 2011).

Os dados relativos ao número de escolas rurais que ofertaram o ensino fundamental entre 2007 e 2010 (Gráfico 2) indicam a força do processo de fechamento de escolas rurais no Rio de Janeiro. Ao contrário do equilíbrio apresentado na observação dos dados da educação infantil, no caso desta etapa, obrigatória e direito público subjetivo ${ }^{\text {iv }}$, a retração da oferta ocorreu em mais da metade dos municípios do estado (54\%) e a não alteração da mesma em $24 \%$ destes. Na contramão deste processo, somente $12 \%$ dos municípios expandiram a oferta de escolas rurais com ensino fundamental, por sua vez, $10 \%$ não ofertaram esta etapa em áreas rurais.

Gráfico 2

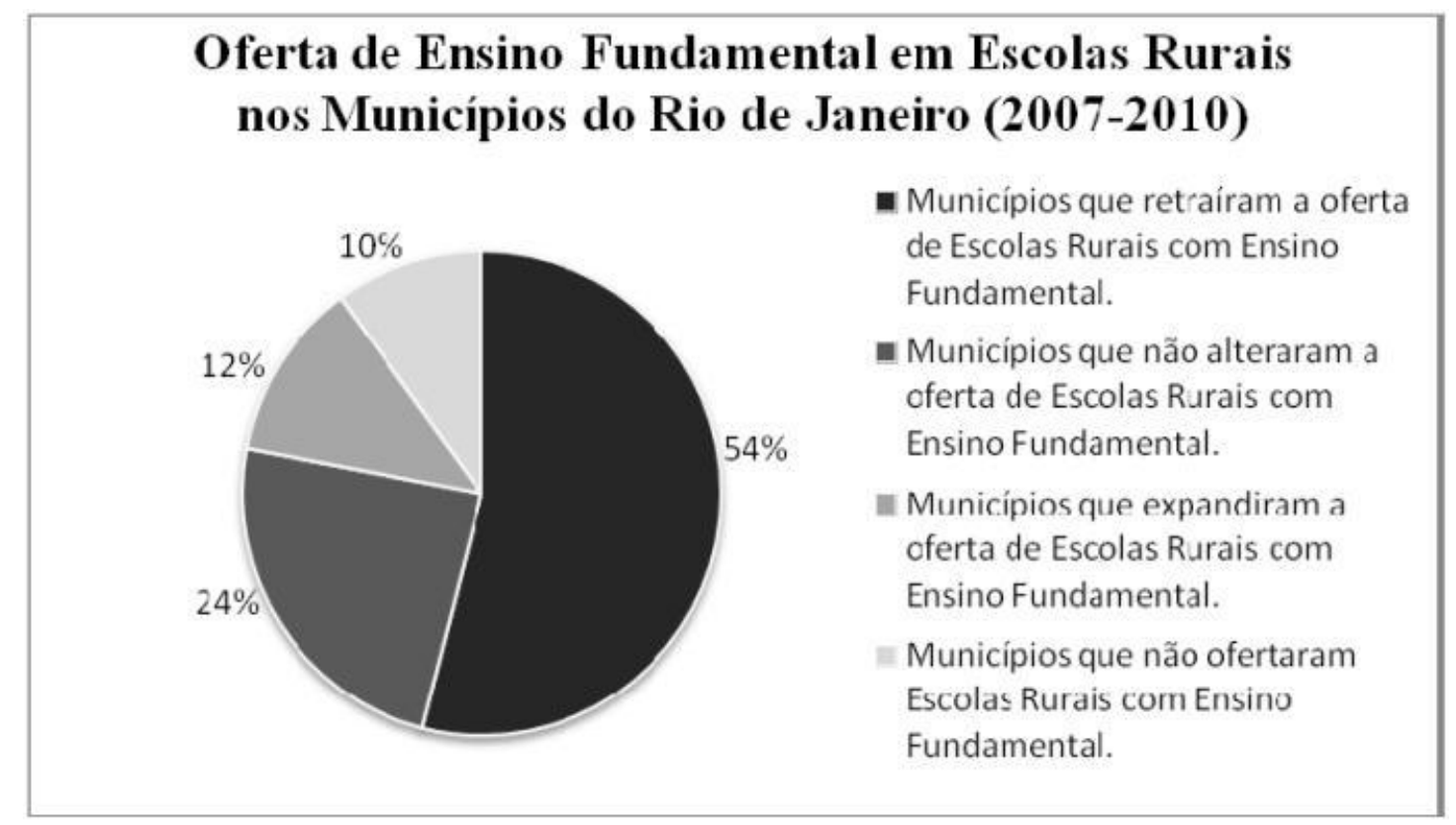

Fonte: Gráfico Organizado a partir de dados dos Indicadores Demográficos e Educacionais (MEC, 2011)

Nesta etapa, que deveria ter uma oferta mais abrangente tanto no campo quanto na cidade, é possível visualizar com mais clareza (Mapa 2) o que parece ser uma reorganização da oferta escolar no 
estado. No mapa a seguir, a predominância do vermelho contrasta com a pouca expressividade do amarelo escuro, isto é, a retração das escolas rurais é predominante no estado enquanto é ínfimo o número de municípios que expandiram a oferta.

Mostra-se relevante a porcentagem dos municípios que não alteraram a oferta (24\%) deixando "intocada" a organização espacial da oferta de ensino fundamental do campo, nem a retraindo nem a expandindo. Novamente visualiza-se a pouca expressividade dos municípios que não ofertaram a etapa neste período, representados novamente na cor cinza.

Outro fato interessante representado no mapa 2 diz respeito à predominância da expansão da oferta escolar rural em alguns municípios que compõem a região metropolitana, como São Gonçalo que expandiu a oferta de ensino fundamental em seis escolas rurais, Nova Iguaçu em cinco, Itaboraí em três e Magé e Seropédica em uma escola rural cada um. Em contrapartida a retração parece ocorrer com mais efetividade nos municípios interioranos.

Mapa 2

\section{Oferta de Ensino Fundamental em Escolas Rurais nos municípios do Rio de Janeiro (2007-2010).}

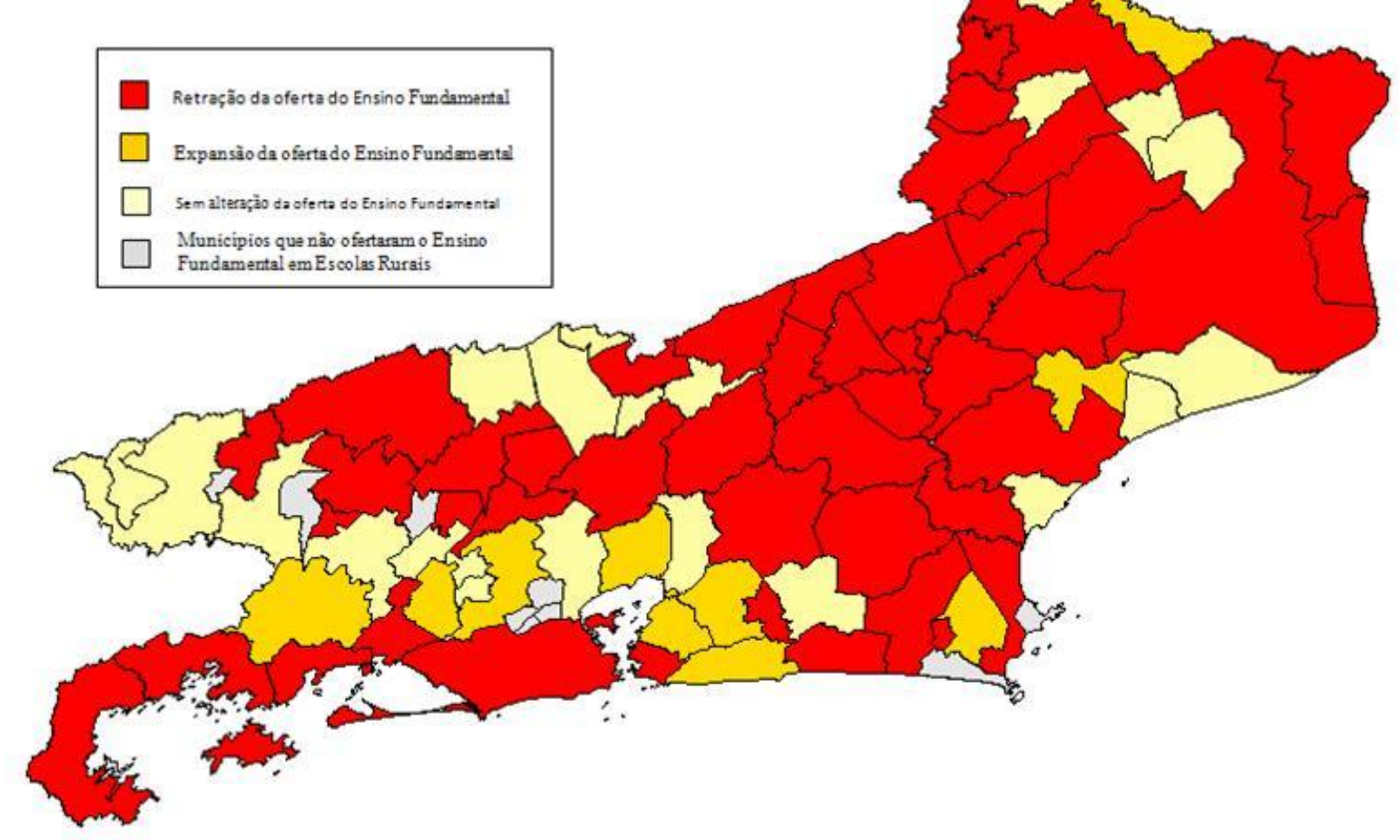

Fonte: Mapa elaborado a partir dos dados dos Indicadores Demográficos e Educacionais 2007-2010 (MEC, 2011).

Na tabela 2 encontram-se elencados os municípios que mais retraíram a oferta de ensino fundamental. Lidera o processo o município de Campos dos Goytacazes, que reduziu a oferta em 19 escolas rurais, seguido por Sapucaia, Cachoeiras de Macacu, São Francisco de Itabapoana, Valença e São Sebastião do Alto.

A redução da oferta em Campos dos Goytacazes em números absolutos representa um número expressivo, porém em termos relativos corresponde a uma redução de 14\% da oferta, percentualmente 
a menor dentre os municípios da tabela 2, já São Sebastião do Alto, que em números absolutos diminuiu a oferta de ensino fundamental em sete escolas, percentualmente retraiu em $50 \%$ a oferta desta etapa no campo, uma redução extremamente expressiva e a maior dentre os municípios que lideraram a retração no período analisado, como dispomos na tabela 2.

Tabela 2

Municípios do Rio de Janeiro que mais Desativaram a Etapa de Ensino Fundamental (2007-2010)

\begin{tabular}{c|c|c}
\hline \hline Colocação & Municípios & Número de Escolas Desativadas \\
\hline $1^{\circ}$ & Campos dos Goytacazes & 19 \\
\hline $2^{\circ}$ & Sapucaia & 10 \\
\hline $3^{\circ}$ & Cachoeiras de Macacu & 8 \\
\hline $4^{\circ}$ & São Francisco de Itabopoana/Valença & 7 \\
\hline $5^{\circ}$ & São Sebastião do Alto & \\
\hline \hline
\end{tabular}

Fonte: Tabela Organizada a partir de dados dos Indicadores Demográficos e Educacionais (MEC, 2011).

No levantamento de dados acerca da oferta de ensino médio em escolas rurais nos municípios do Rio de Janeiro, não é a retração da oferta que chama a atenção e sim a restrição desta na maior parte dos municípios, visto que $61 \%$ destes não ofertaram esta etapa de ensino em nenhuma escola rural entre 2007 e 2010 (Gráfico 3).

Estes dados geram grave preocupação por demonstrarem a impossibilidade de conclusão da educação básica por parte dos jovens do campo, pois não há a oferta do ensino médio. A falta de oferta desta etapa obriga jovens do campo a se deslocarem para a cidade para a conclusão dos estudos, o que nem sempre é possível e viável para os mesmos e suas famílias.

$\mathrm{O}$ atraso escolar dos jovens do meio rural, a impossibilidade de continuarem sua escolarização pela falta de oferta educacional, ou pelas longas distâncias que precisam enfrentar para suprir esta ausência, aliado ao alto custo que isto representa para suas famílias, faz com que parte relevante destes jovens não ascenda a este nível de ensino. Esta privação desencadeia diferentes prejuízos, não só para seu desenvolvimento integral, como para as possíveis contribuições que poderiam trazer às suas famílias e comunidades (OLIVEIRA; MONTENEGRO, MOLINA, 2011. p. 61) 


\section{Gráfico 3}

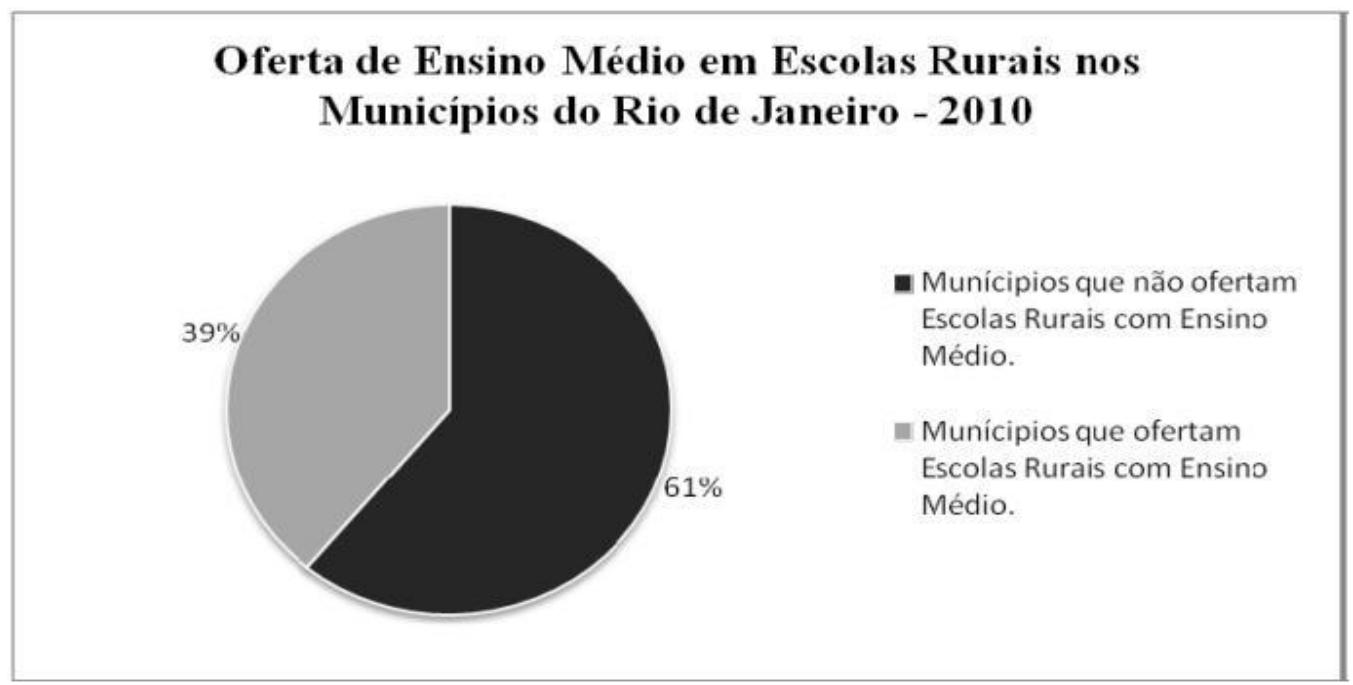

Fonte: Gráfico Organizado a partir de dados dos Indicadores Demográficos e Educacionais (MEC, 2011)

No mapa 3, apesar de visualmente o amarelo claro, indicativo da oferta de ensino médio em ao menos uma escola rural, predominar, a maior parte dos municípios, representados em vermelho, optou pela não oferta desta etapa. Ocorre que em geral a área dos municípios que ofertaram o ensino médio é maior do que a daqueles que não o ofertaram em 2010.

Esta espacialização nos leva a inferir que os municípios menores tendem a restringir ou concentrar a oferta em áreas urbanas, pelo fato de o transporte escolar ter que percorrer curtas distâncias em um tempo relativamente pequeno. Ao contrário, municípios com maior área teriam maior dificuldade no transporte e um tempo de deslocamento relativamente maior, o que poderia influenciar na permanência da oferta no campo. Porém, os dados quantitativos não permitem um aprofundamento mais abrangente, limitando algumas considerações e abrindo margem apenas para inferências.

Importante assinalar que a maior parte dos municípios que ofertaram o ensino médio no período analisado o fez de maneira extremamente restrita. Em sua maioria, a oferta desta etapa foi realizada em apenas uma escola rural, por sua vez, apenas três municípios a ofertaram em mais de três escolas em 2010: Campos dos Goytacazes, em 10 escolas, Seropédica, em seis, e Nova Friburgo em quatro. 


\section{Mapa 3}

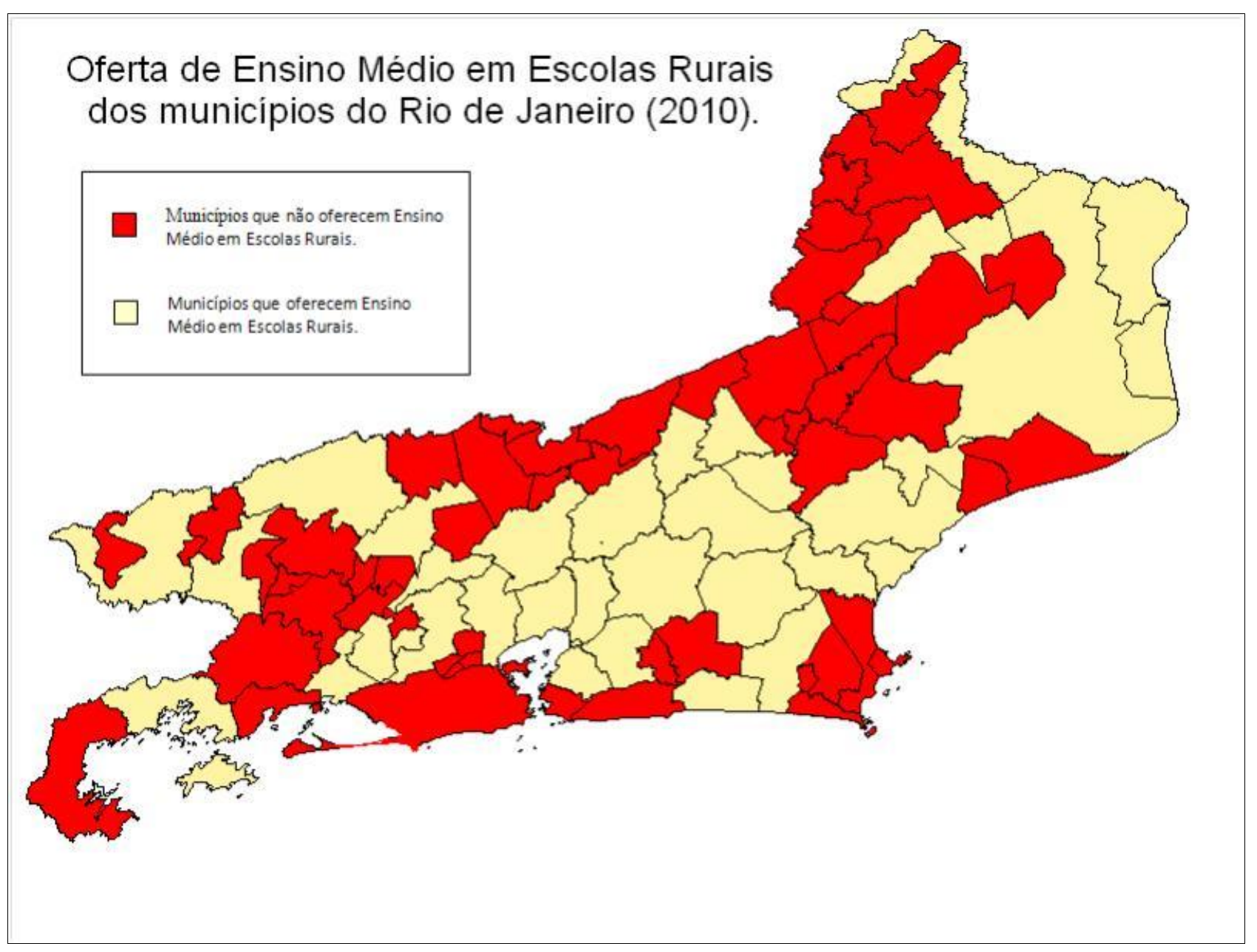

Fonte: Mapa elaborado a partir dos dados dos Indicadores Demográficos e Educacionais - 2010 (MEC, 2011).

A reorganização espacial da oferta escolar no estado parece mais concreta na análise dos dados referentes ao total de escolas rurais em cada município, visto que $47 \%$ destes diminuíram o quantitativo de escolas rurais entre 2008 e $2010^{v}$, enquanto $29 \%$ não alteraram o quantitativo e $11 \%$ sequer possuíram escolas rurais no período (Gráfico 4).

$\mathrm{Na}$ contramão do processo observa-se que somente $13 \%$ dos municípios aumentaram o quantitativo de escolas rurais, atendendo as reivindicações do movimento por uma educação do campo e resoluções (BRASIL/MEC, 2002, 2008) do próprio governo (Gráfico 4). 


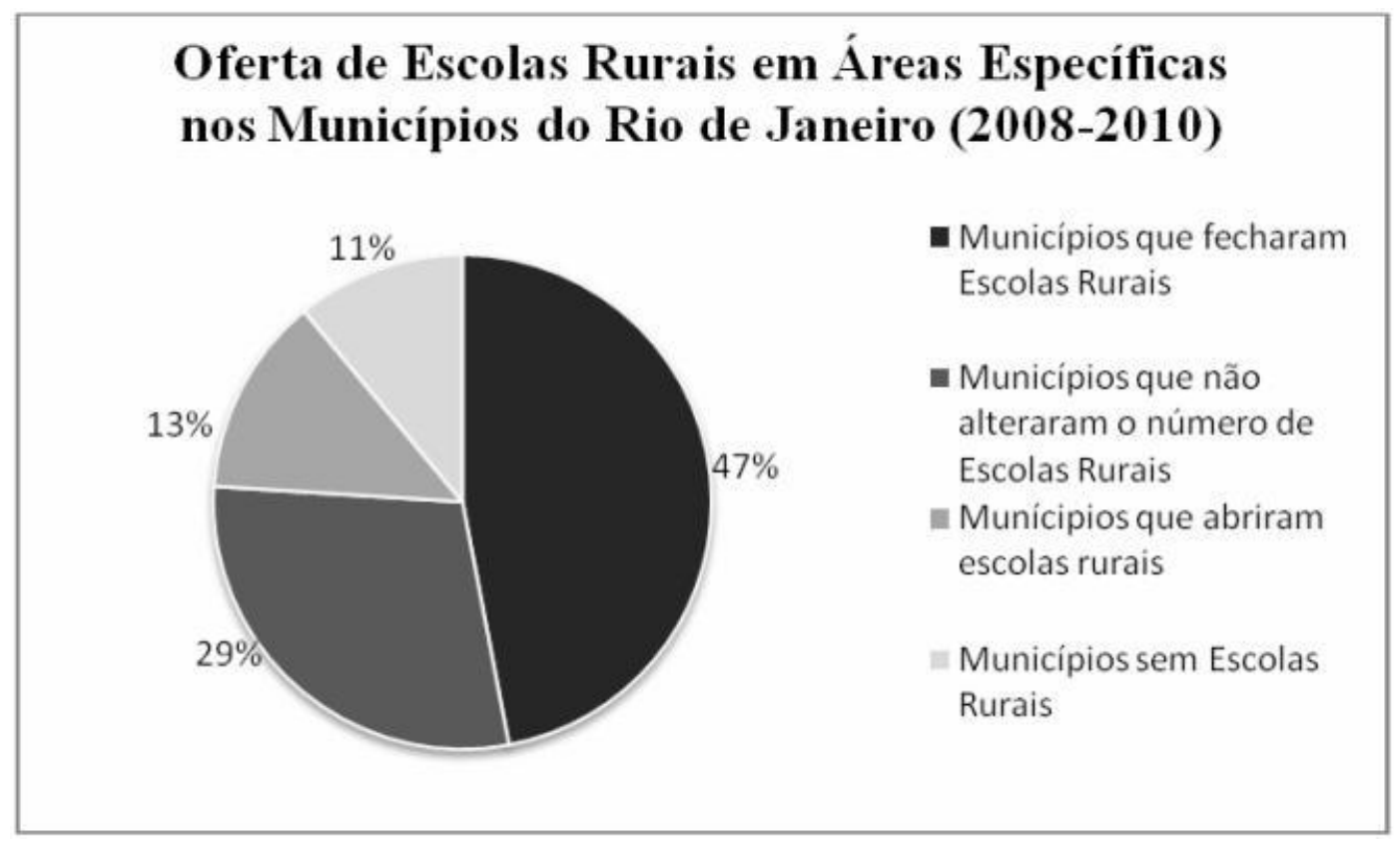

Fonte: Gráfico Organizado a partir de dados dos Indicadores Demográficos e Educacionais (MEC, 2011)

No mapa 4, a predominância do vermelho, indicativo do fechamento de escolas rurais, representa a força e expansão do processo de nucleação de escolas rurais contrastando com os doze municípios em amarelo escuro que expandiram a oferta de escolas rurais: Nova Iguaçu, com mais cinco escolas, Conceição de Macabu e Itaboraí, com mais quatro escolas cada um, Maricá, com mais três escolas, Natividade e Magé, com mais duas escolas cada um, e Cardoso Moreira, Itatiaia, Paraíba do Sul, Paraty, Quissamã e Rio Claro, com mais uma escola rural cada um.

É possível visualizar a pouca expressividade dos municípios que não ofertaram escolas em áreas rurais, sendo estes representados na cor cinza. Cabe apontar a pequena área da maioria destes, o que provavelmente pode pesar na opção pelo transporte escolar. A pouca ou nenhuma existência de áreas delimitadas como rurais nestes municípios igualmente pode ser um fator que determina a não oferta de escolas rurais.

Na tabela 3, visualizam-se os municípios que mais fecharam escolas rurais no período analisado. Enquanto alguns municípios retraíram a oferta menos expressivamente, desativando apenas uma escola, outros o fizeram de maneira extremamente expressiva, como no caso de Cachoeiras de Macacu, Campos dos Goytacazes e Sapucaia. Cabe ressaltar, no entanto, que o fechamento de uma escola já é em si um dado alarmante, principalmente para a comunidade que perde este espaço, além de que, proporcionalmente, pode significar uma expressiva retração.

Em números relativos, dos municípios listados (Tabela 3) o que mais retraiu a oferta foi Sapucaia ao desativar $48 \%$ de sua rede escolar rural em apenas três anos, seguido por Cachoeiras de Macacu, com uma diminuição de 44\%, Valença diminuindo em 19\% sua oferta, São Francisco de Itabapoana com menos $13 \%$ e, finalmente, Campos dos Goytacazes, com uma retração de $8 \%$, relativamente menos expressiva, devido ser este o município com a maior rede escolar rural do estado do Rio de Janeiro. 
Mapa 4

\section{Oferta de Escolas Rurais em Áreas Específicas nos municípios do Rio de Janeiro (2008-2010).}

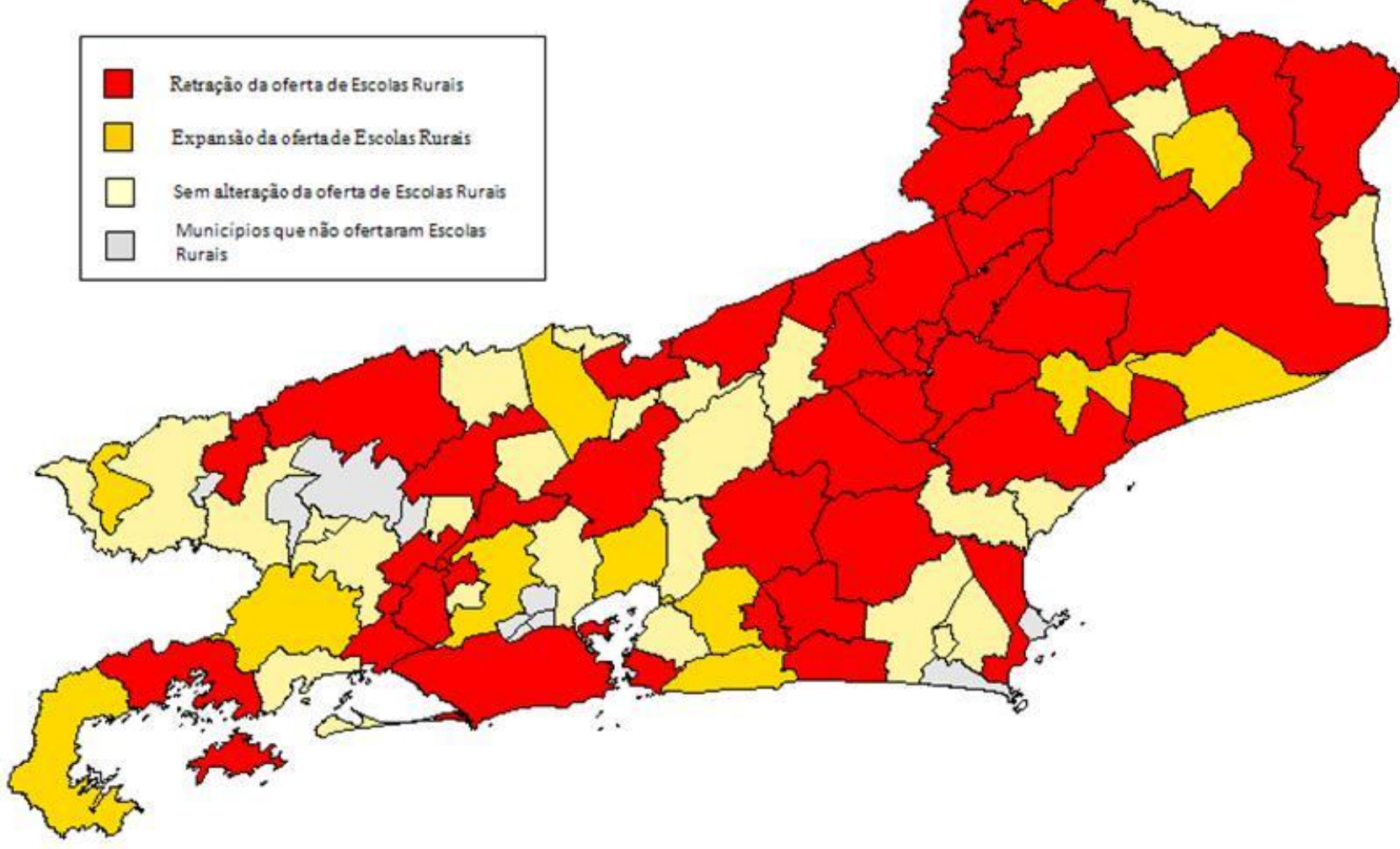

Fonte: Mapa Elaborado a partir dos Dados dos Indicadores Demográficos e Educacionais 2008-2010 (MEC, 2011).

Tabela 3

Municípios do Rio de Janeiro que mais Desativaram Escolas Rurais (2008-2010)

\begin{tabular}{c|c|c}
\hline \hline Colocação & Municípios & Número de Escolas Desativadas \\
\hline $1^{\circ}$ & Cachoeiras de Macacu & 18 \\
\hline $2^{\circ}$ & Campos dos Goytacazes & 13 \\
\hline $3^{\circ}$ & Sapucaia & 10 \\
\hline $4^{\circ}$ & Valença & 8 \\
\hline $5^{\circ}$ & São Francisco de Itabapoana & 7 \\
\hline \hline
\end{tabular}

Fonte: Tabela Organizada a partir de dados dos Indicadores Demográficos e Educacionais (MEC, 2011). 


\section{CONSIDERAÇÕES FINAIS}

Por meio da observação e análise dos dados dos Indicadores Demográficos e Educacionais, foi possível mapear a espacialidade da oferta escolar no campo fluminense e avaliar, levando em consideração outras pesquisas e dados (MST, 2011), a possibilidade de estar em curso uma reorganização espacial da oferta escolar no estado do Rio de Janeiro, que consiste na retração da oferta escolar no campo e na concentração desta nos espaços urbanos.

Os limites deste artigo e dos dados disponibilizados não nos permitem concluir como esta reorganização está sendo executada, assim como, deixam lacunas acerca de alguns dados, como os referentes à expansão da oferta em alguns municípios, principalmente metropolitanos, já que há a probabilidade de mudança de classificação de escolas urbanas e rurais, o que resultaria em uma expansão onde não existiria de fato. Neste sentido, há a hipótese da redefinição de espaços como rurais em municípios do Rio de Janeiro pela luta de assentados e pequenos agricultores e, inclusive, pela busca de mais verbas por parte das prefeituras por conta da criação de políticas educacionais que aumentam os recursos para escolas rurais.

A metodologia de classificação de escolas rurais igualmente aponta algumas limitações. Nos IDE as escolas rurais são divididas em quatro áreas específicas: Escola do Campo, Escola em Área de Assentamento, Escola em Área Remanescente de Quilombola e Escola Comunidade Indígena, porém não há uma explicitação clara sobre como é feita a classificação, existindo algumas alterações bruscas nos dados, principalmente nas Escolas de Assentamento, o que permite o surgimento de interrogações acerca destes dados e sobre esta classificação.

Igualmente, o decreto da educação do campo (BRASIL, 2010), que permite a classificação de escolas rurais em áreas urbanas, desde que atendam alunos do campo, também abre a possibilidade de questionamento dos dados, já que escolas núcleo urbanas ou escolas urbanas em geral podem ser consideradas rurais, dificultando a espacialização real da oferta escolar no campo.

De acordo com os dados, a retração da oferta escolar no campo ficou concentrada nas Escolas do Campo e nas Escolas em Área de Assentamento, já que a redução da oferta foi bem mais significativa nestas áreas. Os dados coletados em geral causam grande preocupação, visto que o direito à escolarização de crianças, jovens e adultos do campo está sendo gravemente ameaçado através da política de fechamento e nucleação de escolas. Tal política parece ocorrer muitas vezes de forma arbitrária, sem diálogo e respeito com as comunidades envolvidas, bem como, sem um controle efetivo por parte do Estado, o que vem causando distorções na interpretação das leis e diretrizes de educação do campo (BRASIL/MEC, 2002, 2008), contrariando o discurso promovido pelo governo e a luta dos movimentos sociais do campo.

Por fim, a disputa entre Estado e Movimentos Sociais pelo processo de escolarização demonstra a importância do espaço escolar e a possibilidade de configuração do mesmo na forma de territórios estatais e/ou contraespaços de resistência. Os movimentos sociais e as comunidades camponesas sofrem um grande golpe com o fechamento de suas escolas, porém a luta pela construção e ocupação destes espaços pelo projeto de educação do campo busca resistir a este processo. Está delineada, portanto, a disputa pelo território escolar do campo e pelo seu projeto de educação. 


\section{NOTAS}

' - Mestra em Educação pelo PPG-Edu da Faculdade de Formação de Professores da UERJ, especialista em Educação Básica, modalidade Ensino de Geografia (FFP/UERJ), graduada em Geografia (FFP/UERJ).

ii CORDEIRO, T. G. B. F. Nenhuma escola fechada! Os impactos da nucleação escolar no embate entre educação rural e educação do campo, 2013. 159 f. Dissertação (Mestrado em Processos Formativos e Desigualdades Sociais) - FFP/UERJ, São Gonçalo, 2013. Orientação: Prof ${ }^{a}$. Dr ${ }^{a}$. Marcia Soares de Alvarenga. Coorientação: Prof. Dr. Paulo Roberto Raposo Alentejano.

iii Programa Nacional de Educação do Campo (BRASIL/MEC, 2013). Para uma análise crítica do Pronacampo ver FONEC, 2012.

iv - Lei de Diretrizes e Bases da Educação Nacional (BRASIL, 1996).

v - Nos IDE, os dados referentes ao número de escolas rurais nos municípios do Rio de Janeiro estavam disponibilizados somente no período entre 2008 e 2010.

\section{REFERÊNCIAS}

BARBOSA, M. C. S; GEHLEN, I; FERNEDES, S. B. A oferta e a demanda de educação infantil no campo: um estudo a partir de dados primários. In: BARBOSA, M. C. S. et al (orgs.). Oferta e demanda de educação infantil no campo. Porto Alegre: Evangraf, 2012.

BRASIL. Decreto 7.352/2010 - Dispõe sobre a política de educação do campo e o Programa Nacional de Educação na Reforma Agrária-PRONERA, Brasília DF, 2010. Disponível em <www.mp.sp.gov.br/portal/page/portal/.../Decreto\%207352-10.doc>. Acesso em 03/01/13.

BRASIL. LDB - Lei n. 9.394 de 20 de dezembro de 1996. Estabelece as diretrizes e bases da educação nacional. Disponível em <http://www.planalto.gov.br/ccivil_03/leis/19394.htm>. Acesso em 22/07/13.

BRASIL/MEC. Portaria $\mathrm{n}^{\mathrm{o}} 86$ - Institui o Programa Nacional de Educação do Campo PRONACAMPO. Brasília/DF: MEC, 2013.

Resolução $n^{\circ} 1$ - Institui diretrizes operacionais para a educação básica nas escolas do campo. Brasília/DF: MEC, 2002.

. Resolução $n^{\circ} 2$ - Estabelece diretrizes complementares, normas e princípios para o desenvolvimento de políticas públicas de atendimento da educação básica do campo. Brasília/DF: MEC, 2008.

CALDART, R. S. Educação do campo. In: CALDART, R. S. et al. Dicionário de educação do campo. RJ: Expressão Popular, 2012.

CORDEIRO, T. G. B. F. Nenhuma escola fechada! Os impactos da nucleação escolar no embate entre educação rural e educação do campo, 2013. 159 f. Dissertação (Mestrado em Processos Formativos e Desigualdades Sociais) - FFP/UERJ, São Gonçalo, 2013.

FONEC. Manifesto do Fórum Nacional de Educação do Campo, 2012. Disponível em < http://www.mst.org.br/Veja-o-manifesto-do-Forum-Nacional-de-Educacao-do-Campo>. Acesso em 22/07/13. 
HAESBAERT, R. O mito da desterritorialização. Rio de Janeiro: Bertrand Brasil, 2011.

MEC. Indicadores demográficos e educacionais. Disponível em

<http://ide.mec.gov.br//2008/index.php>. Acesso em 11/10/2011.

MOREIRA, R. O espaço e o contraespaço: as dimensões territoriais da sociedade civil e do Estado, do privado e do público na ordem espacial burguesa. In: SANTOS, M. et al. Território, territórios: ensaios sobre ordenamento territorial. RJ: Lamparina, 2011.

MST. Educadores lançam manifesto contra o fechamento de escolas rurais. MST: 2011. Disponível em <http://www.mst.org.br/node/12562>. Acesso em 15/10/11.

OLIVEIRA, L. L. N. A; MONTENEGRO, J. L. A; MOLINA, M. C. Panorama da educação do campo. In: MUNARIN, A. et al (org.). Educação do campo: reflexões e perspectivas. Florianópolis: Insular, 2011.

OSLENDER. U. Espacio, lugar y movimientos sociales: hacia una "espacialidad de resistencia". Universidad de Barcelona: Scripta Nova - Revista electrónica de geografia y ciencias sociales, 2002. Disponível em <http://www.ub.es/geocrit/sn/sn-115.htm>. Acesso em 26/04/10.

WANDERLEY, M. N. B. A ruralidade no Brasil moderno: por um pacto social pelo desenvolvimento rural. In: GIARRACCA, N. Una nueva ruralidad en América Latina? Buenos Aires: Clasco, 2001. 